\title{
Use of Information and Communication Technology (ICT) by Extension Officers of the Tea Small Holdings Development Authority of Sri Lanka
}

\author{
B.A.D. Samansiri ${ }^{*}$ and W.A.D.P. Wanigasundera ${ }^{1}$ \\ Postgraduate Institute of Agriculture \\ University of Peradeniya \\ Sri Lanka
}

\begin{abstract}
ABSTRAC: $\quad$ The use of advanced technologies for information dissemination in the tea industry is crucial as tea (Cameliasinensis (L.)Kuntze.) is one of the major foreign exchange earning agribusinesses in Sri Lanka. This study contributes to understand the present status of information needs, use of information and communication technology (ICT) and the contributory factors for use of ICT among extension workers serving the tea small holders. A survey was conducted with a randomly selected representative sample of 101 extension officers of the Tea Small Holdings Development Authority of Sri Lanka using a pre-tested interview schedule, where the questions were designed to generate information on socio-demography, ICT usage, information needs, perception on usefulness and ease-of-use of ICT, and the actual use of ICT. Most of the respondents were above 36 years old, while $65.3 \%$ were with more than 20 years of work experience. The majority (89.1\%) have had diploma level education. Extension workers used to frequently access information on fertilizer and agrochemical availability, tea planting materials and general information on tea cultivation. All respondents owned mobile phones while, $95.0 \%$ had the access to fixed telephones. Only $36.6 \%, 38.6 \%, 47.5 \%$ and $5.0 \%$ of the respondents had access to Internet, e-mail, VCD/DVD/IMM-CD and facsimiles facilities, respectively. The majority (78.2\%) used mobile phones about 4-7 days per week and they had perceived it as highly useful and easy to use material. Besides the high perceived usefulness of Internet, email and VCD/DVD/IMM-CD, use of these facilities was less among older extension workers. There was significant number of respondents who had never undergone any training on ICT use. Regular in-service training and making ICT more accessible can make extension workers more familiar with ICT to get information necessary for their extension activities.
\end{abstract}

Keywords: Extension worker, ICT, information use, tea smallholdings

\section{INTRODUCTION}

Information, in general defined as the "Knowledge communicated or received concerning a particular fact or circumstance" (Wikipedia, 2013a). Information is valuable; however, it is essential to reach large numbers of potential clients, without distorting its quality, to make information more valuable for its use. Information and Communication Technology (ICT) is the integration of telecommunications (telephone lines and wireless signals), computers as well as necessary enterprise software, middleware, storage, and audio-visual systems, which enable users to access, store, transmit, and manipulate information(Wikipedia, 2013b).The

\footnotetext{
1 Department of Agriculture Extension, Faculty of Agriculture, University of Peradeniya, Sri Lanka

* Corresponding author: samansiribad@gmail.com
} 
ICT has the ability to reach a large number of potential clients, without compromising the quality of the information. In addition, ICT can disseminate information in various forms, including text, audio-visual, downloadable and up-loadable files, movies, etc., giving information users several options to inform potential customers about their products. Compared to traditional technology dissemination methods, such as printed material, field demonstrations, face-to-face or group meetings, etc., the ICT is both faster and enables interactive communication.

Use of ICT in agriculture is increasing fast all over the world. The ICT such as mobile communication, electronic mail (email), facsimile, Internet etc. are extensively used for information dissemination in agriculture in developed countries (Lio, \& Liu, 2006). Even if the information on latest technologies are available with the relevant information sources, their retrieval and use for the betterment of the agriculture sector seems to be low in developing countries, due to wide gaps prevailing between information sources and the information users (Nazara, et al., 2004). The ICT facilitates knowledge sharing among researchers, extension workers and farmers, while enabling the information flows by connecting rural agricultural communities to Internet, both in terms of accessing information and providing local content.

Tea is an important crop for Sri Lanka, in terms of export earnings and employment. It contributed $1.1 \%$ of the national GDP in 2011 and $6 \%$ to the total exports from Sri Lanka. The total foreign exchange earnings in 2011 accounted for 164.9 billion SLR or 1.5 billion US\$ (Central Bank of Sri Lanka, 2012).

Although Sri Lanka is renowned for its large scale tea plantations, $70 \%$ of its national tea production is contributed by the tea smallholdings sector. Tea Small Holdings Development Authority (TSHDA) is a government organisation which was established in 1977, under the Tea Small Holdings Development Act No. 35 of 1975, Act No. 36 of 1991 and Act No. 21 of 1997 with the primary mandate of developing the tea small holdings sector in Sri Lanka (Tea Small Holdings Development Authority, 2012). TSHDA delivers extension services to approximately 230,000 tea smallholders in the country by grassroots level 147 Tea Inspector/ Extension Officer currently operated throughout the tea growing area under 26 sub offices in eight regions (Obeysekera, 2009).

The present study focuses on the potential of popular ICT tools in accessing information by the extension workers of TSHDA. Tea smallholders who are the direct recipients of agricultural extension benefits from TSHDA have their own expectations from the extension service. Therefore, one of the major roles of Extension Officers should be communication intervention to provide tea related information required by tea smallholders, in time.

Tea smallholders must receive latest information on tea technology for improving the productivity of their lands. According to a sample survey of tea small holdings conducted in $2008,85 \%$ of the smallholders have accepted TSHDA as the primary source of extension for them and about $75 \%$ had expressed their view on the quality of advices as satisfactory. Meanwhile, about $70 \%$ of smallholders had indicated that ease of access to TSHDA extension workers was satisfactory (Department of Census and Statistics, 2008). A survey conducted in 2005 , in the Galle district by Yapa \& Ariyawardana (2005) revealed that $66 \%$ of the tea small holders have received extension services from the TSHDA, but only $42 \%$ of them have had services at the right time. Since the Extension Officers of TSHDA are the main source of information to tea small holders (Mahaliyanarachchi, 1996), the Extension Officers should be 
equipped with information on latest tea technologies and communication technologies to be efficient in technology dissemination.

According to Obeysekera (2009), individual contacts and group contacts remain the primary extension methods of TSHDA. Moreover, the printed publications are used to strengthen the extension messages delivered. The TSHDA has entered into the cyber extension arena, with the launching of ICT based information dissemination by providing the facilities to receive subsidy information, green leaf prices etc., through SMS (Short Message Service). Any smallholder who supplies green leaf to any bought leaf factory could get their green leaf prices for a particular month by sending a SMS with the details of the month, factory registration number etc. Moreover, several leaflets on nursery management and tea cultivation have been made available in digital format through the website of TSHDA.

\section{ICT use in Sri Lanka}

Sri Lanka's Networked Readiness Index rank for year 2013 is 69 which was 71 in 2012, out of 142 countries. Networked Readiness Index (NRI) is a benchmark of the ICT readiness and the usage of the country (Bilbao-Osorio et al., 2013). This indicates that Sri Lanka has recorded a progress in the area of ICT use.

A survey conducted in 2011 on ICT usage in Sri Lanka reported that the use of standard tools such as word processing, spreadsheets, presentations and databases in day to day work is considerably high. However, only $8 \%$ of the Government sector's permanent staff uses electronic mail for official communication (Information \& Communication Technology Agency of Sri Lanka, 2011).

According to the Telecommunication Regulation Commission of Sri Lanka (2013), in 2012, the mobile phone usage was increasing fast. Mobile subscribers shot up to 18.32 million by end of 2012. The tele-density in Sri Lanka, including cellular phones, is now 116.9 per 100 inhabitants. The high mobile phone usage is the main reason for the high tele-density in the country. The total number of Internet and email subscribers however, was only 1.36 million by 2012, indicating that a very large majority of Sri Lankans are still cut off from the online world (Central Bank of Sri Lanka, 2012).

De Silva \& Ratnadiwakara (2008) showed that $11 \%$ of the total transaction cost of smallholder vegetable farmers in Sri Lanka is informational search costs. When it was broken down further, the information search cost accounted for $25 \%$ of the total growing costs, $20 \%$ of the selling costs and, $75 \%$ of the costs to decide on appropriate crops. They further revealed that the information search cost can be reduced by $33 \%$ by using mobile phones instead of travelling. This proves the potential of ICT to reduce the cost of production of small-growers in Sri Lanka. Jayathilake et al. (2008) reported that the use of ICT applications in the corporate tea sector in Sri Lanka was comparatively high and mobile communication was common among all plantations managers.

\section{ICT use in agricultural extension}

Individual characteristics, information needs and attitudes of extension workers on ICT have the impact on searching and acquiring information from relevant information sources and deliver them to their clientele through appropriate ICT (Koyenikan, 2011). In the wake of the rapid development of ICT during the last few decades, much interest has been taken to exploit 
the advantage of using them in agriculture sector for ensuring their adoption by farmers (Information \& Communication Technology Agency of Sri Lanka, 2010).

ICT can be used as an effective communication tool, particularly where time and distance are constraints. It also has the potential to use as cost effective alternative for some of the traditional technology dissemination methods currently used by the agricultural extension workers. Some of the merits of ICT such as ease of use, declining costs, speed, increasing capacity of data storage, interactivity, and easily merge with different media and the internet make it more appropriate for technology dissemination (Bell, 2002). Moreover, it may also help the technology dissemination process by providing information in a variety of forms to suit a variety of users, in a convenient and timely manner (Nielsen, 1999). The ICT has the ability to overcome barriers of time and distance in technology dissemination as it can facilitate reaching information beyond the local/regional level to the national and international levels. Interactive facilities of ICT such as email, VoIP (Voice over Internet Protocol), video-conferencing, telephones etc. are strengthening the feedback mechanism which is important for the effective dissemination of technology.

Lack of awareness was identified as the main drawback for not using the cyber facilities of the Agrarian Service Centers (ASC) in Sri Lanka. Farmers think that the computer facilities available in the ASC office are meant only for the official use of Agriculture Instructor. Moreover, the negative attitudes of some individuals at senior management levels towards ICT initiatives further worsen this situation (Wijekoon \& Rizwan, 2009).

It is known that the agricultural extension workers operate in widely dispersed locations throughout Sri Lanka. Therefore, there is a need for a variety of communication channels to get information about new technologies from the relevant information sources. Traditional information channels, such as print materials, TV, radio and the extension networks take a considerable time to disseminate agricultural technologies. The ICT may be one of the solutions to reach information effectively and efficiently in this information age. The development of ICT has changed the way society accesses and processes information (Bell, 2002).

\section{Factors influencing the use of ICT}

Katengeza et al. (2011)showed that the use of mobile phone is positively affected by literacy, distance to local market, land size, current value of assets, crop income, and region variations, but negatively influenced by access to electricity. Moreover, the intensity of use is influenced by gender, participation in agricultural projects, ownership of a mobile phone, current asset value, distance to nearest public phone services, and the region variations. A study conducted on extension service by Jimenez (2013) showed that among various ICT tools, radio and mobile phone were found to be the most relevant ICT tools for the extension service delivery in Nigeria. The result showed that significant relationships exist between sex, age, level of education, years of working experience of the extension agents with the level of use of ICTs, but no significant relationship between ICT training of extension workers with the level of ICT use. The study recommended among others that, there should be a periodic review of the use of current ICTs in extension service delivery to facilitate effectiveness in the use of ICT for extension.

Iddings \& Apps (1990) described the factors that seemed relevant to the question "What determines how much a farmer will actually use his/her computer after purchase?" According to them the complexity of farm, degree of external support, age, time, experiences, network, 
availability of information, personality and approach to learning enhanced or diminished a framer's computer use. Moreover, the factors such as lack of ICT proficiency, lack of ICT benefit awareness, too hard to use, lack of technological infrastructure, cost of technology, trust level in the ICT system, lack of training, system integration and software availability could also limit the use of ICT by horticultural farmers in Belgium (Taragola and Lierde, 2005). Warren et al. (2000) reported that, the adoption of ICT is positively associated with the farm size, education level of the farmer and negatively associated with the age of the farmers. Tea producers and poultry farmers in Kurunagala district have stressed that the cost of technology, lack of training, trust level on the ICT system, lack of ICT proficiency and lack of technological infrastructure are thresholds for ICT adoption and use(Jayathilake et al.,2008). A study conducted by Aker (2010) recommended that the training of the extension workers should include computer literacy to enable them access to internet and other electronic information technologies.

Contributions of tea smallholdings sector for national tea production need not to be over emphasized. However, in order to assure the sustainability of smallholdings sector, the extension workers who facilitate the technology dissemination for smallholdings sector should be empowered with latest communication tools available for information dissemination. Several studies conducted in the world, especially in developing countries have shown the merits of popular ICTs to use as development communication tools for the betterment of rural agriculture. Moreover, it is necessary to investigate the types of information extension workers frequently need, the factors that affect on their information seeking behavior and the type of ICT facilities that should be available to get their information needs fulfilled through minimum effort.

This study is designed to find out the facts that are necessary to enlighten the policy makers on the importance of making the extension workers use ICTs efficiently to develop and sustain the tea smallholdings sector in Sri Lanka.

\section{Objectives of the study}

The main objectives of this study were;

to determine the information needs and pattern of ICT use among extension workers of TSHDA

to identify the factors affecting the use of ICT by the extension workers of TSHDA

to make recommendations to improve the ICT usage of the tea small holdings extension service in Sri Lanka

\section{METHODOLOGY}

This study was carried out in all nine major administrative districts viz; Ratnapura, Kalutara, Kegalle, Galle, Matara, Badulla, NuwaraEliya, Kandy and Matale where the major tea grown areas in Sri Lanka. 


\section{Population and sampling procedure}

Table 1. Sample frame of the study

\begin{tabular}{lccc}
\hline Extension staff & Total Population & Sample(N= 101) & $\boldsymbol{\%}$ \\
\hline Assistant Regional Managers & 7 & 4 & 57.1 \\
Senior Tea Inspectors/OICs & 22 & 15 & 68.2 \\
Extension Officers & 141 & 82 & 58.2 \\
\hline Total & 170 & 101 & 59.4 \\
\hline
\end{tabular}

The population for the study consisted of all extension staff of TSHDA. As the study focuses on the use of ICT by the extension workers of TSHDA, this survey was conducted with a randomly selected sample of 101 extension officers, covering $59.4 \%$ of the total population and representing different categories and different tea growing administrative districts (Table $1)$.

\section{Measurement of variables and instruments for data collection}

Data were collected using an interview schedule, which was pre-tested with 10 extension officers of TSHDA who were not included in the sample of study. Questions were designed to generate informationrelated to socio-demographic information, ICT usage, information needs, perception on usefulness and ease-of-use of the ICT and the use of ICT to get tea related information.

Association among the following variable were measured in the present study;

Age, education level, work experience, level of in-service training on ICT and related subjects extension workers received during past three-year period, awareness and use of computer/ICT tools, perceived usefulness (PU) and perceived ease-of-use (PEOU) of ICTs with the use frequencies of mobile phones, fixed-line telephones, Internet, e-mail and VCD/DVD/Interactive multimedia.

Davis (1989) has defined the perceived usefulness (PU) is the degree to which a person believes that using a particular system or technology would enhance his or her job performance, and the perceived ease-of-use (PEOU) is the degree to which a person believes that using a particular system or technology would be free from effort.

Appropriate scales were developed using weighted values for each variables, in consultation with the subject specialists, for this study. Perceived usefulness (PU) and perceived ease-of-use (PEOU) on ICTs were measured with the scale adapted by Davis, (1989), using 15 stages Likert scale.

\section{Data analysis}

Data collected were tabulated, coded and assigned scores, wherever required in order to make them meaningful. Coded/scored data were analyzed using the SPSS software package. Descriptive statistics such as frequency distribution, percentage analysis and weighted averages were used to quantify, describe and to calculate indices for variables. Spearman's-rho correlation analysis was used to test the strength of association among variables. 


\section{RESULTS AND DISCUSSION}

Selected socio-demographic characteristics of respondents were measured, as shown in Table 2. No gender details were given as all the respondents in this study were males.

Table 2. Selected socio-demographic characteristics of extension workers

\begin{tabular}{|c|c|c|}
\hline Socio-demographic characteristics & Frequency $(\mathrm{N}=101)$ & $\%$ \\
\hline \multicolumn{3}{|l|}{ Age } \\
\hline - 35 yrs and below & 8 & 7.9 \\
\hline - $\quad 36-45 \mathrm{yrs}$ & 44 & 43.6 \\
\hline - Above 45 yrs & 49 & 48.5 \\
\hline Total & 101 & 100.0 \\
\hline \multicolumn{3}{|l|}{ Work experience } \\
\hline - Less than 10 yrs & 3 & 3 \\
\hline - $10-20 \mathrm{yrs}$ & 32 & 31.7 \\
\hline - More than $20 \mathrm{yrs}$ & 66 & 65.3 \\
\hline Total & 101 & 100 \\
\hline \multicolumn{3}{|l|}{ Educational qualifications } \\
\hline - Diploma & 90 & 89.1 \\
\hline - Degree & 11 & 10.9 \\
\hline Total & 101 & 100.0 \\
\hline
\end{tabular}

According to Table 2, the extension workers in TSHDA were betweenthe age of 24 and 58 years. According to Wray (2004), scientists aged less than 35 years are considered as young scientists, age between 36 to 45 years are counted as middle-aged scientists, and the scientists aged 46 years and older are considered as old. Similarly, the extension workers in this study were categorized as young, middle - aged and old for the purpose of comparing their use of ICT for extension. As shown in Table 2, 48.5\% were above 45 years old while $43.6 \%$ were between 36 - 45 years and the balance $7.9 \%$ of respondents were 35 years and below.

As shown in the same table, the majority $(65.3 \%)$ have achieved more than 20 years of work experience while $31.7 \%$ have achieved 10 to 20 years of work experience and the balance $3 \%$ has gained only less than 10 years of work experience. A relatively higher percentage of more experienced extension workers indicate that these extension workers, in general, work in the tea sector for a long time; thus, knowledgeable about needs of the smallholdings with respect to tea related information need for small tea growers. The majority $(89.1 \%)$ of the respondents had diploma level education and the balance, had completed a degree level education.

\section{Information needs}

Extension workers cannot be effective in their responsibilities to their clientele, if they are found to be deficient in information on necessary subjects. It is on that basis the investigation of information needs of the extension workers was undertaken in this study. 
Table 3. Extension workers' perceived Information needs $(\mathbf{N}=101)$

\begin{tabular}{lcc}
\hline Information need & Weighted Average & Rank \\
\hline Fertilizer and agrochemicals availability & 99.5 & 1 \\
Tea planting materials & 93.3 & 2 \\
General tea cultivation & 93.5 & 3 \\
Green leaf prices & 89.0 & 4 \\
Fertilizer and agrochemicals prices & 87.0 & 5 \\
Pest \& diseases related Information & 87.1 & 6 \\
Fertilizer and agrochemicals dosages & 81.0 & 7 \\
Agro-meteorological Information & 70.0 & 8 \\
Auction prices of tea & 54.5 & 9 \\
Information on tea manufacturing & 52.0 & 10 \\
\hline
\end{tabular}

According to Table 3, extension workers were more concerned about the information on fertilizer and agrochemical availability in the local market, followed by the tea planting materials and general information on tea cultivation. They were least interested in information about tea manufacturing and auction tea prices. The reason could be that the extension workers of TSHDA do not involve much on technology dissemination on tea manufacturing by nature of their duties.

\section{ICT use of extension workers}

The focus of this study is to explore the extension worker's ICT use behavior and how it could relate with their age, work experience, education qualification, in-service training and attitude on ICT etc. Table 4 shows the availability or accessibility of selected ICTs through the official or personal means.

Table 4. Frequency of ICT usage by extension workers

\begin{tabular}{lrr}
\hline \multirow{2}{*}{ Type of ICT } & \multicolumn{2}{c}{ Availability/Accessibility } \\
\cline { 2 - 3 } & $\mathbf{N}$ & $\mathbf{\%}$ \\
\hline Mobile phones & 101 & 100 \\
Fixed telephones & 96 & 95.0 \\
VCD/DVD/IMM-CD & 48 & 47.5 \\
E mail facilities & 39 & 38.6 \\
Internet & 37 & 36.6 \\
Facsimiles & 5 & 5.0 \\
\hline
\end{tabular}

Use of common ICT was evaluated by inquiring the availability or accessibility to the mobile telephones, land telephones, facsimiles, Internet, email and CD/DVD/IMM-CD facilities in their work place or at home. As shown in Table 4, the availability of mobile phone among the respondents was $100 \%$ while the access to fixed phones was $95.0 \%$. Only $5.0 \%$ of respondents had the access to facsimiles. Having Internet connectivity wasreported by $36.6 \%$, but $38.6 \%$ use e-mail. Two respondents said that they get the email documents through the email accounts of their subordinates. Out of the computer-based ICT, $47.5 \%$ reported that they had access to VCD/DVD/IMM-CD. 


\section{Familiarity and use of communication/Internet services and computer software}

Respondent's awareness and the use of common computer software, telecommunication services and Internet services investigated in this study are shown in Table 5.

Table 5. Awareness and use of communication/Internet services and software

\begin{tabular}{lcc}
\hline Software and Services & \% Aware $(\mathbf{N = 1 0 1})$ & \% Use (N=101) \\
\hline Use of common Internet services & & \\
Face book & 95.0 & 27.7 \\
Google & 88.1 & 35.6 \\
You Tube & 53.5 & 30.7 \\
Skype & 47.5 & 16.8 \\
& & \\
Use of telecommunication technologies & \\
ADSL & 78.2 & 38.5 \\
CDMA & 74.3 & 23.6 \\
GPS & 14.9 & 5.9 \\
Wi-Fi & 10.9 & 5.0 \\
& & \\
Use of common computer software & 95.0 \\
MS Words & 100 & 87.1 \\
MS Excel & 100 & 70.3 \\
MS PowerPoint & 100 & 8.9 \\
Adobe Photoshop & 50.5 & \\
\hline
\end{tabular}

Scale of the awareness and use of selected computer software, Internet service and communication tools were used only as indicators of familiarity of common facilities and services of ICT, among the participants.

Facebook was ranked the most popular social network in 2011 (Stelzner, 2011). According to Table 5, despite the fact that $95 \%$ of respondents were aware of the FaceBook, only $27.7 \%$ reported that they used it. Awareness of Google which is the most popular web search engine in 2011 (Stelzner, 2011) was $88.1 \%$, but only 35.6\% was found to be using it. You Tube, most popular video-sharing website (Stelzner, 2011) and Skype, popular voice-over-IP service, were known to $53.3 \%$ and $47.5 \%$, respectively, but only $30.7 \%$ and $16.8 \%$ had opted to use them.

The respondents were questioned to infer their awareness on new communication techniques and the level of usage. As shown in Table 5, majority (78.2\%) of respondents were aware on ADSL and $74.3 \%$ on CDMA. However, the usage was $38.5 \%$ and $23.6 \%$ for ADSL and CDMA, respectively. The awareness and usage of Global Positioning System (GPS) and Wi-Fi were comparatively poor among extension workers.

Use of the popular software packages were also investigated through the survey. All the respondents were well aware about the most common computer software packages such as, MS Word, MS Excel and MS Power Point. The usage of such packages was also at a 
satisfactory level. However, the awareness and the usage of Adobe Photoshop, the most popular photo editing software, amongst the respondents, were found to be poor.

Table 6. In-service training on the use of ICT and related subjects

\begin{tabular}{|c|c|c|}
\hline \multirow{2}{*}{ In-service training } & \multicolumn{2}{|c|}{ Training opportunity } \\
\hline & Frequency & $\%$ \\
\hline \multicolumn{3}{|l|}{ Duration of programs } \\
\hline No any training & 26 & 22.6 \\
\hline 1 day & 51 & 44.3 \\
\hline $2-4$ days & 17 & 14.8 \\
\hline 5 - 7 days & 16 & 13.9 \\
\hline More than 7 days & 05 & 4.3 \\
\hline Total & $115 *$ & 100 \\
\hline \multicolumn{3}{|l|}{ Frequency of attendance } \\
\hline None & 26 & 22.6 \\
\hline Once & 75 & 65.2 \\
\hline Twice & 10 & 8.7 \\
\hline More than twice & 04 & 3.5 \\
\hline Total & $115 *$ & 100 \\
\hline
\end{tabular}

* Multiple responses

As shown in Table 6, $4.3 \%$ of the respondents have undergone more than 7 days in-service training, $13.9 \%$ for 5 - 7 days, $14.8 \%$ for 2 - 4 days and $44.3 \%$ for 1 day in-service training on the use of ICT and related subjects. However, there were $22.6 \%$ respondents who have never undergone any kind of in-service training on ICT use in their career. Majority (65.2\%) of the participants have attended the training programs only once.

A survey conducted with the objectives to ascertain the level of ICT use in the government sector and, specifically, to find out the information on the personnel handling ICT work, their qualifications and the types of training provided to them, revealed that self study and on-the-job training were the preferred types of training provided by government organization for employees handling ICT related work. Moreover, it was found that training provided to achieve academic and professional qualifications and trade certifications were among low priorities of government organizations (Information \& Communication Technology Agency of Sri Lanka (2011).

\section{Use of ICT tools for technical information}

Table 7 shows the extension worker's ICT use pattern for getting information required to enhance their knowledge by acquiring necessary information for carrying out their duties efficiently. The mobile phone is the communication technology that has been mostly used by the extension officers of TSHDA followed by the land telephones for getting information from the relevant information sources. Uses of VCD/DVD and Interactive Multimedia CDs, Internet and e-mail were average in getting information. Use of facsimile was very rare in getting information. 
Table 7. Use of ICT to get information from sources $(\mathrm{N}=101)$

\begin{tabular}{lcccc}
\hline ICT & $\begin{array}{c}\mathbf{4}-\mathbf{7} \text { days/wk } \\
(\mathbf{\%})\end{array}$ & $\begin{array}{c}\mathbf{0 - 3} \text { days/wk } \\
(\mathbf{\%})\end{array}$ & $\begin{array}{c}\mathbf{1 - 3} \text { days per } \\
\text { month }(\boldsymbol{\%})\end{array}$ & $\begin{array}{c}\text { Never } \\
(\mathbf{\%})\end{array}$ \\
\hline Mobile phones & 78.2 & 21.8 & 0.0 & 0.0 \\
Fixed telephones & 44.6 & 30.7 & 19.8 & 5.0 \\
Facsimiles & 0.0 & 2.0 & 3.0 & 95.0 \\
Internet & 6.9 & 14.9 & 14.9 & 63.4 \\
E mail & 7.9 & 25.7 & 5.0 & 61.4 \\
VCD/DVD/IMM-CD & 8.9 & 27.7 & 5.9 & 57.4 \\
\hline
\end{tabular}

According to Table 7, majority $(78.2 \%)$ respondents stated that they used mobile phones about 4-7 days per week, as it is convenient to get information by mobile phones. Next to mobile phones, $44.6 \%$ of respondents have used fixed telephones to get information, about 4-7 days per week. 95\% have never used facsimiles, while majority have never used the Internet (63.4\%), e-mail (61.4\%) and VCD/DVD/IMM-CD (57.4\%) for getting information. In general, mobile phone is the mostly used communication channel followed by fixed telephone, VCD/DVD/IMM-CD, email, Internet and facsimiles.

\section{Extension worker's perception on ICT}

Extension worker's perception on usefulness and the ease of use of ICT were measured using a Likert scale. The items in the scale asked respondents to agree or disagree with statements using 1-5 steps of the scale with end points of "strongly agree" and "strongly disagree." Two items each for perceived usefulness and perceived ease of use for all ICT tools were included in these scales.

Table 8. Weighted mean score of the perception on ICT

\begin{tabular}{lccccc}
\hline Perception on ICT & \multicolumn{5}{c}{ mean score } \\
\cline { 2 - 6 } & $\begin{array}{c}\text { Mobile } \\
\text { phones }\end{array}$ & $\begin{array}{c}\text { Fixed } \\
\text { telephones }\end{array}$ & Internet & e-mail & $\begin{array}{c}\text { VCD/DVD/ } \\
\text { IMM-CD }\end{array}$ \\
\hline Perceived usefulness & 4.29 & 3.12 & 3.05 & 3.07 & 3.09 \\
Perceived ease of use & 3.70 & 3.51 & 2.09 & 2.16 & 2.69 \\
\hline
\end{tabular}

As shown in Table 8, most respondents have perceived that all ICTs used in the study are useful for getting required information. However, except the Internet, e-mail and VCD/DVD/ IMM-CD and other ICTs were found to be easy to use.

\section{Factors affecting ICT usage by extension workers}

The present study investigated the relationships among extension worker's age, work experience, awareness and the use of computer/ICT tools, in-service training on ICT, perceived usefulness, perceived ease of use of ICT and ICT use scores which indicate the level of ICT use for getting information by the extension workers. Spearman's rho correlation coefficient indicates the strength of association among variables at 95\% probability levels. 
Table 9. Correlations among characteristics of extension workers and the ICT use scores

\begin{tabular}{lccccc}
\hline Variables & \multicolumn{5}{c}{ Spearman's rho Correlation Coefficient } \\
\cline { 2 - 6 } & $\begin{array}{c}\text { Mobile } \\
\text { use }\end{array}$ & $\begin{array}{c}\text { Fixed phone } \\
\text { use }\end{array}$ & $\begin{array}{c}\text { Internet } \\
\text { use }\end{array}$ & $\begin{array}{c}\text { e-mail } \\
\text { use }\end{array}$ & $\begin{array}{c}\text { VCD/DVD } \\
\text { use }\end{array}$ \\
\hline Age & 0.119 & $0.241^{*}$ & $-0.361^{*}$ & $-0.271^{*}$ & -0.141 \\
Work experience & 0.133 & $0.243^{*}$ & $-0.291^{*}$ & $-0.321^{*}$ & -0.132 \\
In-service training on & 0.221 & 0.214 & $0.417^{*}$ & $0.317^{*}$ & $0.427^{*}$ \\
ICT & & & & & \\
Awareness and use of & $0.313^{*}$ & 0.208 & $0.378^{*}$ & $0.428^{*}$ & 0.228 \\
computer and ICT tools & & & & & \\
Perceived usefulness & $0.513 * *$ & $0.527^{* *}$ & $0.312^{*}$ & $0.328^{*}$ & $0.428^{*}$ \\
Perceived ease of use & $0.529 * *$ & $0.329 *$ & 0.218 & 0.212 & 0.213 \\
\hline * Significant at 95\% probility level & ** Significant 99\% probbility level & &
\end{tabular}

* Significant at $95 \%$ probability level, $\quad * *$ Significant at $99 \%$ probability level

As shown in Table 9, there is a significant correlation of mobile phone use with the awareness on computer and ICT tools, perceived usefulness and perceived ease of use of the mobile phones.Study conducted by Jimenez (2013) in Nigeria showed a significant relationship between sex, age, level of education, years of working experience of the extension agents with the level of ICT use. However, no significant relationships were seen among the use of mobile phone with age, work experience and ICT training of extension workers in the present study. The same study proves that there is no significant relationship between ICT training of extension workers with the level of ICT use. According to Telecommunication Regulation Commission (2013), the tele-density in Sri Lanka is high (116.9 per 100 inhabitants) due to high usage of mobile phone in the country. Most of Sri Lankans use mobile phones irrespective of their age, work experiences, formal or informal education on ICT, etc. However, those who are knowledgeable on different technologies/facilities available in ICTs, perceived useful and ease of use of the mobile phones tend to use them more frequently.

According to the findings, correlation between fixed telephone use with age, work experience, perceived usefulness and perceived ease of use of fixed telephones show positive and significant. The possible reason could be that, with aging, people tend to remain using the communication channels that they used for years, However, no significant relationships were seen between fix telephone use with in-service training on ICT and the awareness on computer/ICT tools.

There was no significant correlation found with perceived ease of use in Internet, email and VCD/DVD/IMM-CD use for information retrieval. Low accessibility of Internet (36.6\%), email facilities (38.6\%) and VCD/DVD/IMM-CD facilities (47.5\%) found among extension workers could be the possible reason for their negative perceptions on the ease of use of the above facilities. However, the actual uses of Internet and email facilities have significant correlation with in-service training on ICT, the awareness on computer/ICT tools and perceived usefulness of both Internet and email. Age and work experience were found to be negatively and significantly correlated with the use of both Internet and email facilities. It indicates that at present old and experienced extension workers do not take much interest in using Internet and email facilities for searching information on tea.

There is a significant correlation of the use of VCD/DVD/IMM-CD with in-service training on ICT and perceived usefulness of VCD/DVD/IMM-CD for getting information. It seems that 
proper in-service trainings on ICT and extension worker's perception on the usefulness of VCD/DVD/IMM-CD enhance the use of VCD/DVD/IMM-CD for getting information. No significant correlations were found with the awareness and use of computer/ICT tools and perceived ease of use with the use of VCD/DVD/IMM-CD; while the age and work experience were negatively correlated but were not significant at $95 \%$ probability level. It seems that with aging, the extension workers are not interested in using VCD/DVD/IMM-CD to get information.

\section{CONCLUSION}

This study found that TSHDA consisted of majority of middle-aged and old extension workers (more than 36 year old) and majority of the extension workers with more than 20 years of work experience. The highest educational qualification that the majority had was diploma in agriculture. However, about $11 \%$ of the respondents had degree level educational qualifications.

Extension workers frequently access the information on fertilizer and agrochemical availability in the local market, followed by the tea planting materials and general information on tea cultivation. Such information needs can be fulfilled through mobile or fixed telephones without spending time for traveling or using other expensive communication means, as all the respondents owned mobile phones, while $95 \%$ had the access to land phones. Moreover, the extension worker's perception on usefulness and ease of use of both fixed telephones and mobile phones significantly and positively correlated with their use of fixed telephones and mobile phones for getting information; both telephones have the higher potential to become the best ICT tool for extension workers of TSHDA to get information for their extension delivery.

In-service training and the awareness of computer/ICT tools and use of them found to be positively correlated with the use of ICT by extension workers. Among them, the relationships of Internet, email and VCD/DVD/IMM-CD use with the level of in-service training were significant. Therefore, the use of such ICTs for information retrieval by the extension workers can be improved through frequent in-service training programs on ICT use and continuously update them on new developments of ICTs for making them more knowledgeable on computer and ICTs.

Extension worker's age and work experiences showed a negative relationship with the use of Internet, e-mail and VCD/DVD/MM-DVD facilities. Therefore, it is necessary to make it compulsory to the old and experienced extension workers to attend in-service training programs, to get their knowledge and skills on the use of ICTs for information retrieval improved.

It can be concluded that making the extension workers knowledgeable and skilled on computer and ICT tools, through regular in-service training programs and improving their accessibility to ICTs, could make the extension workers more familiar with ICTs to get information necessary for their extension activities. 


\section{REFERENCES}

Aker, J.C. (2010). Dial "A" for Agriculture: Using Information and Communication Technologies for Agricultural Extension in Developing Countries, (online) (Accessed on 12. 07.2013) Available at http://www.cgdev.org/publication/dial-agriculture-review-information-and-communications

Bell, M. (2002). Internet Delivery of Short Courses for Farmers: A Case Study of a Course on Precision Agriculture', RIRDC Publication No. 02/085, Rural Research and Development Corporation, Canberra (online).(Accessed on 12.05.2013).Available at http://www.rirdc.net/ict-content/uploads/2005/11/internetdelivery-casestudy.pdf

Bilbao-Osorio, B., Dutta, S. and Lanvin, B, (2013), The Global Information Technology Report 2013, Growth and Jobs in a Hyper connected World, World Economic Forum, Geneva, p 263.

Central Bank of Sri Lanka (2012). Annual Report 2012, Central Bank of Sri Lanka.

Davis, F.D. (1989). Perceived usefulness, perceived ease of use, and user acceptance of information technology. MIS Quarterly, 13(3), 319 - 340

Department of Census and Statistics. (2005), Census of Tea Small Holdings in Sri Lanka. Colombo, Sri Lanka.

De Silva and Ratnadiwakara, P. (2008).Using ICT to Reduce Transaction Costs in Agriculture through Better Communication: A case study from Sri Lanka, LIRNEasia. (online). (Accessed on 12.07.2013). Available at

http://www.lirneasia.net/wp-content/uploads/2008/11/transactioncosts.pdf

Iddings, R.K. and Apps, J.W. (1990). What influences farmers' computer use? Journal of Extension.28(1), 15 - 19.

Information \& Communication Technology Agency of Sri Lanka. (2010). National ICT Workforce Survey, $e$-SRI LANKA DEVELOPMENT PROJECT, Cr:3986-CE, ICTA/CON/QCBS/P1/248, Colombo, Sri Lanka, pp 10-25.

Information \& Communication Technology Agency of Sri Lanka. (2011). Survey Report on ICT Usage in the Government Sector, Information \& Communication Technology Agency of Sri Lanka (ICTA), pp 11-35.

Jayathilake, H.A.C.K., Jayaweera, B.P.A. and Waidyasekera, E.C.S. (2008). ICT Adoption and Its' Implications for Agriculture in Sri Lanka, Journal of Food and Agriculture, 1(2), 54 63.

Jimenez, A. (2013). ICTs for Extension Service Delivery: Implication for Agricultural Development in Nigeria.e-Agriculture. (online). (Accessed on: 03.08.2013). Available at: http://www.e-agriculture.org/content/icts-extension-service-delivery-implication-agricultural -development-nigeria 
Katengeza, S.P., Okello J.J. andJambo, N.N. (2011). Use of Mobile Phone Technology in Agricultural Marketing: The Case of Smallholder Farmers in Malawi, ICT Research and Development in Africa, 2(2).

Koyenikan, J.M. (2011). Extension workers' access to climate information and sources in Edo State Nigeria, Archives of applied science research, 3(4), 11 - 20

Lio, M. and Liu, M.C. (2006). ICT and agricultural productivity: evidence from cross-country data. Agricultural Economics, 34,221 - 228

Mahaliyanarachchi, R.P. (1996). Dissemination of Information to Tea Small Holders in Sri Lanka, Unpublished Ph.D. Thesis, University of Peradeniya, Sri Lanka.

Nazara, S.I., Wisana, D.G.K. and Friawan, D. (2004). Determining the Impact of Informationand Communication Technology (ICT) on Decent Work in Indonesia, Demographic Institute, Faculty of Economics - University of Indonesia, (online). (Accessed on 12.08.2013), Available at http://www.jil.go.jp/english/events_and_information/documents/ann04_indonesia.pdf

Nielsen, R.L. (1999). Cyberspace and Agricultural Technology Transfer: An Indiana Experience', Purdue University, West Lafayette, presentation, (online). (Accessed on: 12.06. 2013), Available at: http://www.agry.purdue.edu/ext/corn/talks/cyberspace/index.htm,

Obeysekera, K.G.B. (2009). Agricultural Extension in the Tea Smallholdings Sector in Sri Lanka.pp 160- 181. In:Sivayoganathan, P. (Ed.) Meeting Farmer Needs, Proceeding of Agriculture Extension Conference, University of Peradeniya, Sri Lanka

Stelzner, M.A. (2011). Report on How Marketers are Using Social Media to Grow Their Businesses. Social Media Marketing Industry (Online).(Accessed on 13.07.2013). Available at: http://www.socialmediaexaminer.com/SocialMediaMarketingReport2011.pdf

Taragola, N. and Lierde, D.V. (2005). Adoption of ICT in horticulture: Confronting scientists' opinions with practice in Flanders, Belgium, (online) (Accessed on 14.07.2013) Available at: www.efita.net/apps/accesbase/bindocload.asp?d=6239 \& $\mathrm{t}=0 \ldots$

Tea Small Holdings Development Authority, (2011). Annual Report 2012, Tea Small Holdings Development Authority, Colombo, Sri Lanka

Telecommunication Regulation Commission (2013). Telecommunication Regulation Commission (www.trc.gov.lk) (online).(Accessed on 12.07.2013). Available at http://www.trc.gov.lk/statistics/statistical-overview.html

Warren, M.F., Soffe, R.J. and Stone, M.A.H. (2000). Farmers, computers and the Internet: a study of adoption in contrasting regions of England'. Farm Management, 10(11), 665 - 684.

Wijekoon, R. and Rizwan, M.F.M. (2009). ICT Initiative for Agriculture Extension of the Department of Agriculture, Experiences and Challenges in Agricultural Extension. pp. 296-329: In:Sivayoganathan, C. (Ed.) Meeting Farmer Needs, Proceeding of Agriculture Extension Conference, University of Peradeniya, Sri Lanka, 
Wikipedia.(2013a). (online). (Accessed on 02.07.2013), Available at http://en.wikipedia.org/wiki/Information

Wikipedia. (2013b). (online). (Accessed on 02.07.2013), Available at http://en.wikipedia.org/wiki/Information_and_communications_technology\#cite_note-2

Wray, K.B, (2004). Middle-Aged Scientists are Most Potent, Is science a young person's game?: Department of Philosophy, State University of New York, Oswego. (online).

(Accessed on 02.07. 2013). Available at

http://www.the-scientist.com/?articles.view/articleNo/16055/title/Middle-Aged-Scientists-are -Most-Potent/

Yapa, K.D.A.J. and Ariyawardana, A. (2005).Willingness to pay for a fee-based extension service by tea smallholders in Galle District, Sri Lankan Journal of Agricultural Economics, 7, p. 84 . 